Flanagan, M. (2015). [Review of the book Media and translation: An interdisciplinary approach, by D. Abend-David (Ed.)]. Linguistica Antverpiensia, New Series: Themes in Translation Studies, 14, 223-226.

\title{
Abend-David, D (Ed.) (2014). Media and translation: An interdisciplinary approach. New York, NY: Bloomsbury. 365 p.
}

Media and Translation: An Interdisciplinary Approach is a collection of essays spanning a wide variety of academic fields such as Translation, Film Studies, Literary Theory, (Critical) Cultural Studies, Humour Studies, Communication Studies, New Media, Marketing and Advertising. Even though there has been a dramatic increase in publications on media and translation over the last decade, new research in this area is in no way superfluous. As a result, this collection contributes fully to the body of research exploring the relation and codependence of the fields Media and Translation. Abend-David aims to deliver a collection which is heterogeneous and versatile, and he succeeds in this endeavour. The emphasis throughout Media and Translation is on offering the reader a sense of the variety of research being conducted within this broad field, and on demonstrating the possibilities of sharing theoretical frameworks and methodologies across disciplines.

Achieving a "truly interdisciplinary" (p. xii) collection can present challenges, and in his editor's note, Abend-David highlights how diversity among contributors can ultimately threaten "intellectual unity" (p. xii). However, the decision to publish a heterogeneous collection of contributions within Media and Translation can be considered a unique characteristic of this volume, which provides the reader with a mix of voices and opinions from, for the most part, interdisciplinary scholars.

The fourteen chapters presented in this volume are organised into seven parts. Abend-David provides a helpful title and introduction to each part, which summarise the chapters that follow and contextualise their relationships. At times, however, it is difficult to understand the logic behind the division of parts and the titles provided. One example is the title of Part 2, Subtitling and Dubbing, when the chapters that follow concern only dubbing. Another is the unsuitable title to Part 5, Translation, Communication, and Globalization, considering the contents of the chapters. A possible solution is to broaden some of the current titles and group chapters that share a common thread. Nevertheless, these minor points do not disturb the reading experience and are perhaps simply an example of challenges during the process of editing (p. xii).

Part 1 (Film Translation and Adaptation) presents three chapters. Heiss (Chapter 1) discusses the problems associated with dubbing multilingual films, in particular, the lack of attention paid to instances of code-mixing and code-switching in films dubbed from German to Italian. Omissions often result in the multilingual reality depicted in the original film being removed or hidden in the dubbed version. Heiss calls for an inclusion of translation modalities in the dubbing process to ensure an increased awareness of the "complex social reality" (p. 22) in the target 
culture. Zabalbeascoa and Voellmer (Chapter 2) also address multilingual film translation, but from a descriptive perspective. They offer a theoretical model, which considers all AVT elements that have a communicative value, to account for translation instances that are considered outside of translation proper (from source L1 to target L2) (Jakobson, 1959, p. 232) and refer to these instances as intratextual translation (L3). It is envisaged that this model can offer new transfer options in the case of multilingual film translation, which, to date, has seen multilingualism in film translation reduced or even erased. Their use of Inglourious Basterds as a case-study is an ideal source to validate the L3 proposal. Pettit (Chapter 3) closes Part 1 by examining code-switching and language variation in the South African gangster film genre, using the films Tsotsi and Hijack Stories and their English subtitled and French subtitled/dubbed versions. While language variation is accounted for in the subtitled and dubbed versions (mostly through informal lexis and colloquial terms), code-switching is generally not specified. Instead, compensatory devices are used to reinforce the gangster subculture.

Part 2 (Subtitling and Dubbing) comprises two complementary chapters on dubbing. Baños (Chapter 4) discusses the topic of prefabricated fictional dialogue, which often loses its spontaneity as a result of scriptwriting principles, and the resulting issues facing AV translators during the dubbing process. Following this, Audissino (Chapter 5) focuses on three types of formal interference which dubbing can have on a film's form: (1) sound homogeneity, (2) characterisation and (3) dialogue adaptation. She calls for a more scrupulous work ethic, knowledge of film aesthetics, and receptive understanding of film art to avoid these interferences (p. 115).

Part 3 (Media and Computer Translation), unfortunately, offers only one contribution (Chapter 6). However, Remael, Van Waes and Leijten's essay is an excellent introduction to those not already familiar with process research within Translation Studies. This chapter outlines two experiments. The first experiment investigates the relations between error production and three live subtitling production modes. The second experiment explores the effects of respeaker behaviour using two different respeaking methods. The scholars also include two additional, important sections: a comparison of respeaking and simultaneous interpreting, and a detailed description of their logging tool, Inputlog.

Part 4 (Between Literary and Media Translation) presents readers with two papers that discuss the relationship between film, literature and translation. Raine (Chapter 7) sees subtitling, in contrast to literary translation, as an "adaptive" process, one which does not "obliterate the original" (p. 7), and discusses the role digital technologies can now play in subtitling practices. In Chapter 8 , Heller introduces us to the world of film adaptation and literary translation of fantasy literature. She describes how fantasy is viewed as a transmedia genre, no longer restricted to literary forms. However, she prefers to think of fantasy as "a 
cultural collection of texts" or "multiple-media channels" (p. 174), providing examples from publications such as The Spiderwick Chronicles by Holly Black and Tony DiTerlizzi.

Part 5 (Translation, Communication, and Globalization) moves the focus to audience reception/perception of audiovisual texts, with two contributions. Chiaro (Chapter 9) reports on the work of Forlì researchers, who conducted various audience reception/perception studies on Italian end-users, in an attempt to measure the impact of translation on verbally expressed humour. Preliminary findings indicate that culture and the quality of translations both impact audience response. Patterson and Chyutin (Chapter 10) discuss teaching the film Waltz with Bashir to their college students, with a focus on teaching trauma in translation. To engage this text fully, they opted to also engage their students through a reception study. Even though the editor notes in the introduction to this part how these two contributions complement each other, this connection is not abundantly clear to the reader.

Part 6 (Global News and Politics) focuses on the translation and reception of newspaper reports and news broadcasts. Pan (Chapter 11) develops a critical analytical framework drawing on three models: Critical Discourse Analysis, Appraisal Theory, and Narrative Theory, to study the stance mediation in English-Chinese news report translation. The findings show stance mediation exists in the Chinese news agency, despite their claims that they are "faithful" to the source texts (p. 263). Turning to news broadcasts, Samuel-Azran, Lavie-Dinur and Karniel (Chapter 12) examine if blind assessments of Al-Jazeera English (AJE) news items among Jewish-Israelis receive higher credibility and professionalism ratings than video broadcasts that include network identifiers. The authors believe the findings illustrate that "prejudice against AJE $[\ldots]$ constitutes a perception that Arab-produced material is biased" (p. 281).

Part 7 (Promotions, Commercials, Tweets, and Minisodes) introduces the reader to less explored areas of Media and Translation. Bucaria (Chapter 13) discusses the adaptation of paratexts (e.g., blogs, promos, teasers, trailers for two TV programmes, Glee and Breaking Bad, for Italian audiences. For both series, fewer Italian paratexts were found compared with the US market. However, within the target culture, a higher number of Glee paratexts were found. Further research is needed to fully appreciate the impact paratexts have on the target audience. The final contribution from Cui and Zhao (Chapter 14) explores advertisement translation from English-Chinese with presupposition as the key concept in their analysis. They present examples of altered cultural images in advertisements, and argue for the effectiveness of such changes. However, it is disappointing that the authors do not refer to the term transcreation, which has come into common use within industry and academia within the last five years. Furthermore, the discussion on presupposition fills the majority of the essay, not allowing much room for 
a discussion of examples taken from the corpus. I would disagree with the editor's comment in the introductory note (p. 292) and argue that the complexity of advertisement translation (or transcreation) is not demonstrated fully in this contribution.

In addition to the seven main parts, the reader is provided with three noteworthy extras: (1) a list of author biographies; (2) a list of abstracts following Chapter 14, but this location is not very obvious to the reader; and (3) a useful, reader-friendly glossary follows each chapter. However, apart from in Chapters 2 and 12, it would have been convenient if the words in the glossary were identified somehow in the running text.

Some formatting inconsistencies have been noted. Normally chapters follow a numbering section/sub-section format, but Chapters 3, $7,8,10$ rely on headings/sub-headings alone. Chapter 5 does not contain any numbering or headings. It is difficult to read Figures in Chapter 12 because of a lack of distinguishing colours. The Introduction is excluded from the numbering format in Chapters 4 and 14. However, these are minor blemishes.

In the preface to this volume, Susan Bassnett explains that the essays in this collection exemplify a new trend of interdisciplinary research, which is the result of a changing, more globalised world, and she welcomes the diverse approach adopted in this volume. I agree. This is an essential contribution to Media Studies and Translation Studies, and it will surely attract a diverse audience, including academics and students alike.

\section{References}

Jakobson, R. (1959). On linguistic aspects of translation. In R. A. Brower (Ed.), On translation (pp. 232-239). Cambridge, MA: Harvard University Press.

\section{Marian Flanagan}

Aarhus University, Denmark marfl@bcom.au.dk 